\title{
EXPERIÊNCIA E AFETO EM DEWEY: UMA CONEXÃO ORGÂNICA
}

Marcus Vinicius da Cunba ${ }^{1}$

\section{Resumo}

Experiência é uma das noçóes mais importantes da concepção educacional desenvolvida no século XX, e John Dewey é o autor mais citado quando o assunto é experiência. Este trabalho analisa a noção de experiência na filosofia de John Dewey, focalizando especialmente o livro Experiência e educação. Esse exame é complementado por reflexôes de Jim Garrison em Dewey and Eros e por alguns excertos de Arte como experiência de Dewey.

Palavras-chave: John Dewey; Pragmatismo; Teoria Educacional; Filosofia da Educaçáo.

\section{Abstract}

Experience is one of the most important notions of the educational conception developed in 20th century, and John Dewey is the most mentioned author when the issue is experience. This work analyses the notion of experience in John Dewey's philosophy, focusing specially the book Experience and education. This exam is complemented by reflections of Jim Garrison in Dewey and Eros and by some excerpts of Art as experience de Dewey.

Keywords: John Dewey; Pragmatism; Educational Theory; Philosophy of Education.

1 Marcus Vinicius da Cunha é Professor Associado do Departamento de Educação, Informação e Comunicação da Faculdade de Filosofia, Ciências e Letras de Ribeirão Preto - USP

E-mail: mvcunha@hotmail.com

Educ. foco, Juiz de Fora, v. 20 , n. 2 , 



\section{EXPERIÊNCIA E AFETO EM DEWEY: UMA CONEXÃO ORGÂNICA²}

\section{INTRODUÇÁO}

Grande parte - se não a totalidade - das novas pedagogias, desenvolvidas no decorrer século XX e ainda hoje presentes, prescreve valorizar a experiência dos educandos para a obtençáo de sucesso no processo educativo. O termo "experiência" assume várias conotações, dependendo da corrente filosófica a que se filiam os teóricos, o que dificulta sensivelmente o estabelecimento de consensos e até mesmo interlocuçôes efetivas na área.

Neste texto, cujo caráter é meramente introdutório, examinarei a noção de "experiência” em John Dewey (18591952), talvez o filósofo mais mencionado por quem se reivindica adepto de inovaçóes educacionais. Sua notoriedade decorre do fato de ter examinado o tema em inúmeros trabalhos, sendo considerado por muitos estudiosos “o filósofo da experiência”. ${ }^{3}$ Tomarei por base o livro Experiência e educação de John Dewey, complementando a sua análise com as consideraçóes de Jim Garrison apresentadas em Dewey and Eros, no intuito de destacar a relevância dos fatores afetivos no conceituação deweyana.

Vale observar que Experiência e educação foi publicado em 1938, quando Dewey já havia escrito grande parte de sua obra filosófica e educacional, como se pode ver pela seguinte amostragem deseustítulos: ${ }^{4}$ Comopensamos (1910, reformulado

2 Este texto foi adaptado da comunicação que apresentei no evento "O pensamento educacional de Dewey em debate", realizado na Faculdade de Educação da UFRJ em 4 de novembro de 2010, com a presença de Renato José de Oliveira e Susana de Castro Amaral Vieira, a quem agradeço a hospitalidade e as contribuiçóes oferecidas.

3 Sobre Dewey, em consonância com a abordagem aqui adotada, ver Teixeira (1978), Amaral (1990), Cunha (1994) e Pappas (2008).

4 Indicarei em português as obras cujas traduçôes foram publicadas no Brasil. 
em 1933); Democracia e educação (1916); Reconstrução em filosofia (1920); Human nature and conduct (1922); Experience and nature (1925); The quest for certainty (1929); Arte como experiência (1934). No mesmo ano de Experiência e educação, Dewey publicou também Logic: the theory of inquiry e, no ano seguinte, Teoria da valoração. Experiência e educação, portanto, é um livro de reflexóes amadurecidas, cuja elaboração visava a delimitar os posicionamentos do autor perante novas e antigas concepções de educação, conforme esclarecerei logo mais.

\section{O OBJETIVO GERAL DO LIVRO}

Em Experiência e educação, Dewey visa esclarecer os pontos essenciais de sua proposta educacional, toda ela fundamentada na noção de "experiência", buscando contraporse a duas outras concepçóes: a tradicional e a progressiva. A oposição de Dewey ao ensino dito tradicional é bastante conhecida; o que se destaca nesse livro são as reservas do autor, nem sempre bem compreendidas, à educação progressiva, uma das vertentes do amplo movimento de renovação do ensino iniciado no final do século XIX em países da Europa e nos Estados Unidos.

Experiência e educação é um livro importante porque, dentre outros motivos, demarca os limites entre a filosofia educacional deweyana e determinadas orientaçôes do ensino renovado táo em voga no início do século passado - e, de certo modo, ainda hoje -, fundamentadas na tese de que o aluno deve ocupar o centro do processo educacional, o que, consequentemente, desloca para segundo plano a interferência do professor e os programas de ensino.

A discordância de Dewey ante os dois modelos educacionais, o antigo e o novo, é fundamentada na crítica aos dualismos, tanto no campo da filosofia quanto no da educaçáo. O primeiro parágrafo do livro é bastante significativo, nesse aspecto: 
Costuma formular suas crenças em termos de "um ou outro", "isto ou aquilo", entre os quais não reconhece possibilidades intermediárias. Quando forçado a reconhecer que náo se pode agir com base nessas posições extremas, inclina-se a sustentar que está certo em teoria mas na prática as circunstâncias compelem ao acordo. (DEWEY, 1971, p. 3)

Esse modo de pensar examinado por Dewey tem reflexos na filosofia da educação, cuja história é "marcada pela oposição entre a idéia de que educação é desenvolvimento de dentro para fora e a de que é formação de fora para dentro"; há pensadores que defendem que a educação deva ser baseada nos "dotes naturais" dos educandos, enquanto outros definem o trabalho educativo como "um processo de vencer as inclinaçôes naturais e substituí-las por hábitos adquiridos sob pressão externa” (DEWEY, 1971, p. 3).

No primeiro capítulo e em outras passagens do livro, Dewey explica os termos opostos em que se dividem a escola tradicional, de um lado, e escola progressiva, de outro, compondo um cenário que pode ser visualizado de maneira sumária pelo seguinte quadro de oposiçóes:

\begin{tabular}{|l|l|}
\hline \multicolumn{1}{|c|}{ Escola Tradicional } & \multicolumn{1}{c|}{ Escola Progressiva } \\
\hline $\begin{array}{l}\text { Informações, habilidades } \\
\text { e regras morais originadas } \\
\text { no passado }\end{array}$ & $\begin{array}{l}\text { Informações, habilidades e } \\
\text { regras morais correspondentes às } \\
\text { necessidades vitais atuais dos alunos }\end{array}$ \\
\hline $\begin{array}{l}\text { Transmissão desses } \\
\text { conteúdos e preparação } \\
\text { para o futuro }\end{array}$ & $\begin{array}{l}\text { Valorização das oportunidades do } \\
\text { presente }\end{array}$ \\
\hline $\begin{array}{l}\text { Aluno como receptor de } \\
\text { conteúdos de matérias; } \\
\text { aprendizagem como } \\
\text { aquisição por meio de } \\
\text { professores, que são } \\
\text { comunicadores de } \\
\text { conhecimentos }\end{array}$ & $\begin{array}{l}\text { Aluno como ser ativo; aprendizagem } \\
\text { pela experiência }\end{array}$ \\
\hline
\end{tabular}




\begin{tabular}{|l|l|}
\hline \multicolumn{1}{|c|}{ Escola Tradicional } & \multicolumn{1}{c|}{ Escola Progressiva } \\
\hline $\begin{array}{l}\text { Disciplina externa; } \\
\text { imposição de cima para } \\
\text { baixo, sustentada na } \\
\text { autoridade do professor }\end{array}$ & $\begin{array}{l}\text { Atividade livre (interna); expressão e } \\
\text { cultivo da individualidade }\end{array}$ \\
\hline $\begin{array}{l}\text { Conteúdos estáticos e } \\
\text { acabados, próprios de } \\
\text { uma realidade que não se } \\
\text { transforma }\end{array}$ & $\begin{array}{l}\text { Conteúdos oriundos de um mundo } \\
\text { em permanente mudança }\end{array}$ \\
\hline $\begin{array}{l}\text { Predomínio do adulto; } \\
\text { permanência do velho }\end{array}$ & $\begin{array}{l}\text { Predomínio da criança; emergência } \\
\text { do novo }\end{array}$ \\
\hline
\end{tabular}

Os termos - colocados em destaque no quadro - que definem a escola tradicional refletem um compromisso educacional com a estabilidade e a permanência de valores e comportamentos, enquanto os termos - igualmente destacados no mesmo quadro - que caracterizam o movimento progressivista sugerem o exato oposto. $\mathrm{O}$ distanciamento e as barreiras entre ambos impede qualquer trânsito entre os dois polos conceituais.

\section{PROBLEMA E SOLUÇÁO}

Considerando a vigência desses dualismos, Dewey elege um problema a enfrentar: necessitamos de uma nova filosofia da educação. Não se trata de recusar integralmente os princípios da educaçáo progressiva, mas é preciso reconhecer que todos os princípios são, "em si mesmos, abstraçôes"; eles se tornam "concretos somente nas consequências que resultam de sua aplicação” (DEWEY, 1971, p. 7).

O parâmetro adotado é típico da concepção filosófica pragmatista a que Dewey se filia, consistindo em jamais descartar a priori quaisquer formulaçóes teóricas, entendendo que a validade de cada uma delas ou a superioridade de uma sobre outra náo se define pelo debate estritamente teórico, mas pela avaliação das consequências resultantes da aplicação 
da teoria em situaçóes concretas da vida, de modo geral, e da educação, em particular.

Exatamente porque os princípios acima indicados são de tamanho alcance e tão fundamentais, é que tudo depende da interpretação que lhes for dada ao pô-los em prática na escola e no lar. (...) A filosofia geral da educação nova pode ser boa e certa, mas a diferença em princípios abstratos não é o que vai decidir o modo por que as vantagens morais e intelectuais neles contidas se irão concretizar na prática. (DEWEY, 1971, p. 7)

$\mathrm{Na}$ análise acerca da "autoridade", compreende-se o posicionamento de Dewey (1971, p. 8-9) perante os dualismos:

Quando se rejeita o controle externo, o problema é como achar os fatores de controle inerentes ao processo de experiência. Quando se refuga a autoridade externa, não se segue que toda autoridade deva ser rejeitada, mas antes que se deve buscar fonte mais efetiva de autoridade. Porque a educação velha impunha ao jovem o saber, os métodos e as regras de conduta da pessoa madura, não se segue, a não ser na base da filosofia dos extremos de "isto-ou-aquilo", que o saber da pessoa madura náo tenha valor de direção para a experiência do imaturo.

Ao contrário disso, se a educação tomar por base a "experiência pessoal" de todos os envolvidos no processo, professores e alunos, pode-se obter, na prática, "contatos mais numerosos e mais íntimos entre o imaturo e a pessoa amadurecida" e, assim, "mais e não menos direção e orientação por outrem". Dewey, portanto, não rejeita a necessidade orientar e dirigir os educandos, mas defende que essa meta náo pode ser alcançada pela imposiçáo de objetivos externos à experiência dos alunos, ou seja, conferindo à palavra "autoridade" a conotação consolidada pela visão tradicional de educação. Não se trata de recusar a autoridade representada 
pelo professor, mas de conferir a ela o caráter de cooperação com a experiência do aprendiz.

A solução, segundo Dewey (1971, p. 9) está em uma "filosofia bem elaborada dos fatores sociais que operam na constituição da experiência individual”. Como os princípios abstratos não resolvem o problema na prática - ao contrário, levantam novos problemas -, faz-se necessária uma "nova filosofia da experiência”. Essa nova teoria é esboçada no segundo capítulo do livro, no qual Dewey (idem, p. 14) toma, como ponto de partida, a afirmação de que existe "conexão orgânica entre educação e experiência pessoal”, o que torna a filosofia da educação "comprometida com alguma espécie de filosofia empírica e experimental".

Essa última ideia, expressão de determinado posicionamento teórico, não se explica por si mesma; ao contrário, ela faz parte do problema que Dewey se dispóe a enfrentar: antes de tudo, precisamos entender o que é a experiência, para então podermos conhecer o significado do empirismo que pleiteamos assumir. A questáo central, portanto, reside em responder à indagação sobre "o que é experiência”.

\section{CONEXÂO ORGÂNICA}

Ao abordar o vínculo entre experiência e educação, Dewey utiliza a expressão "conexão orgânica" para indicar a estreita relação entre os dois termos, que são, para ele, mutuamente dependentes, inseparáveis, constituindo uma só unidade. A mesma expressão é utilizada por Dewey em outras passagens de sua obra, usualmente para exprimir esse mesmo significado.

No oitavo capítulo de Reconstrução em filosofia, por exemplo, ao comentar os termos "indivíduo" e "sociedade", tal qual se apresentam nas teorizaçóes da filosofia social, Dewey (1959b, p. 177) diz que "a sociedade e os indivíduos são, entre si, correlativos, formando um todo orgânico". Nesse mesmo 
capítulo, como faz em Experiência e educação, Dewey também pretende romper certo dualismo, defendendo, dessa vez, a indissociabilidadede entre o indivíduo e a sociedade; e alerta para o fato de que de nada adianta afirmarmos abstratamente tal indissociação, pois é preciso analisar, na prática, em cada caso particular, qual é a relação concreta entre determinada coletividade e seus membros (DEWEY, 1959b, p. 184).

Nota-se que o referencial adotado por Dewey é sempre a prática, em oposição à abstração, à teorização, à idealização, uma vez que afirmaçóes teóricas constituem um problema, não uma solução. Em Reconstrução em filosofia, o que está em pauta é a defesa de que as teorizaçóes são apenas "pontos de partida de pesquisas acerca de cada instituição da comunidade", e Dewey (1959b, p. 184-185) considera "surpreendente" o "desperdício de energia" que se dá quando insistimos em "discutir problemas de ordem social em termos de conceitos universais".

\section{O QUE É EXPERIÊNCIA?}

Voltemos à questão: o que é a experiência, ou melhor, o que é uma experiência verdadeiramente educativa? Podemos dizer "verdadeiramente" porque, segundo Dewey (1971, p. 16), nem toda experiência é educativa: "Tudo depende da qualidade da experiência por que se passa”. O critério para julgar a qualidade ou o valor de uma experiência consiste em examinar o que sucede após a experiência, ou seja, é preciso levar em conta as experiências futuras. Dewey (idem, p. 14) afirma que é "deseducativa toda experiência que produza o efeito de parar ou distorcer o crescimento em direção a novas experiências posteriores",

Dewey (1971, p. 14-15) apresenta uma série de situaçóes em que uma experiência pode ser deseducativa, no sentido de dificultar novas experiências futuras. Por exemplo, se a experiência produzir "dureza, insensibilidade, incapacidade de responder aos apelos da vida"; se "aumentar a destreza em alguma atividade automática”, mas, com isso, habituar
Experiência e afeto em Dewey: uma conexão orgânica
Educ. foco, Juiz de Fora v. 20 , n. 2 , jul. 2015 / out. 2015 
"a pessoa a certos tipos de rotina"; se for "imediatamente agradável", mas ainda assim "concorrer para atitudes descuidadas e preguiçosas". Por fim, as experiências serão de baixa qualidade quando forem "desconexas e desligadas umas das outras", não se articulando "cumulativamente", gerando "hábitos dispersivos, desintegrados, centrífugos", e, ainda, se impedirem o aprendizado do "domínio de si mesmo".

Para Dewey (1971, p. 16), a qualidade de uma experiência deve ser avaliada segundo dois critérios: o "imediato", que diz respeito a ser "agradável ou desagradável”, e o "mediato", relativo à "sua influência sobre experiências posteriores". Se o primeiro soa "óbvio e fácil de julgar", o segundo oferece certa dificuldade, consistindo em um "problema para o educador", cuja tarefa é "dispor as coisas para que as experiências, conquanto não repugnem ao estudante e antes mobilizem seus esforços, não sejam apenas imediatamente agradáveis, mas o enriqueçam e, sobretudo, o armem para novas experiências futuras".

No terceiro capítulo de Experiência e educação encontram-se dois princípios que ajudam a compreender o problema da qualidade de uma experiência: continuidade e interação. O primeiro refere-se ao que já foi dito anteriormente: uma experiência possui mais qualidade quando afeta experiências subsequentes. Dewey (1971, p. 28-29) reafirma que uma experiência de qualidade deve atuar sobre as "condiçóes objetivas em que ocorrerão novas experiências"; uma experiência qualitativamente superior é a que "desperta curiosidade, fortalece a iniciativa e suscita desejos e propósitos suficientemente intensos para conduzir uma pessoa aonde for preciso no futuro"; o valor de uma experiência "não pode ser julgado, se não na base de para que e para onde ela se move".

Sobre o princípio da interação, Dewey (1971, p. 35) afirma: "Qualquer experiência normal é um jogo entre dois grupos de condiçóes", as "internas" e as "externas", sendo que ambas, tomadas em conjunto, constituem uma "situação". As condiçóes "externas" ou "objetivas" remete aos fatores 
ambientais que controlam a experiência individual, enquanto as condiçôes "internas" dizem respeito aos traços inerentes da pessoa que passa pela experiência.

Os princípios de interação e continuidade apresentamse de tal modo inseparáveis que podemos caracterizá-los como constituintes de uma conexão orgânica. São dois termos que "não se separam um do outro"; eles "se interceptam e se unem"; são "aspectos longitudinais e transversais da experiência", conclui Dewey (1971, p. 37):

Diferentes situaçôes sucedem umas às outras. Mas, devido ao princípio de continuidade, algo é levado de uma para outra. Ao passar o indivíduo de uma situaçáo para outra, seu mundo, seu meio ou ambiente se expande ou se contrai. (...) O que aprendeu como conhecimento ou habilitação em uma situação torna-se instrumento para compreender e lidar efetivamente com a situação que se segue.

Dewey (1971, p. 37-38) considera ainda que a "unidade substancial" do processo reside no "fator individual, elemento integrante da experiência". Assim, uma "personalidade completamente integrada" somente "existe quando as sucessivas experiências se integram umas com as outras" e quando essa personalidade pode "edificar o seu mundo como um universo de objetos em perfeito relacionamento”.

\section{A PRÁTICA COMO CRITÉRIO}

Nos quatro capítulos seguintes de Experiência e educação, Dewey analisa as oposições que separam a educação tradicional da educação progressiva, buscando mostrar de que maneira é possível superá-las. Não farei a exposição desses capítulos, pois isto nos conduziria para muito longe do objetivo estabelecido no presente texto; vou ater-me apenas às ideias que finalizam o livro. 
No último capítulo da obra, Dewey (1971, p. 95) afirma que, no decorrer de sua exposição, deu como certo o princípio de que a educação deva ser baseada na experiência, "que é sempre a experiência atual de vida de algum indivíduo". Em outras palavras, ele informa que tomou por pressuposto o vínculo orgânico entre educação e experiência, caracterizando "experiência" como algo estritamente individual. Afirma também que não argumentou "para a aceitação deste princípio", nem procurou justificá-lo; esforçou-se apenas para mostrar o aspecto geral de uma educação que siga o "método científico no desenvolvimento das possibilidades da experiência sempre crescente e em expansão".

A única possibilidade de fracasso de uma proposta de educação que siga tais princípios reside no modo como esses mesmos princípios - que são enunciados teóricos - forem colocados em prática pelos educadores. Com esta afirmação, Dewey mostra-se fiel ao que explanou anteriormente: a questão central da educação não reside nos princípios abstratos que buscamos para nortear a nossa prática, mas na própria prática, ou seja, no modo como interpretamos e colocamos aqueles princípios em ação em situaçôes concretas. E os princípios expostos por Dewey não fogem a essa regra: eles poderão ser acatados por nós quando, na prática, mostrarem a sua efetividade.

\section{EXPERIÊNCIA E AFETOS}

Para conferir maior amplitude à noção deweyana de "experiência", é importante observar que, em Democracia e educação, Dewey (1959a, p. 153) comenta que uma experiência nunca é "primariamente cognitiva", pois seu valor "reside na percepção das relaçóes ou continuidades" a que nos remete. Se a experiência não é primariamente cognitiva, então o que ela é, primariamente?

Ao discorrer sobre o conceito de "reflexão" ou "investigação" em Arte como experiência, Dewey (p. 109110) diz que o processo de pensar reflexivamente é o que 
propicia uma "experiência singular", expressão que define o que ocorre "quando o material vivenciado faz o percurso até a sua consecução". Temos uma experiência singular quando a experiência é "integrada e demarcada no fluxo geral da experiência proveniente de outras experiências", como acontece quando concluímos uma obra qualquer, quando solucionamos uma questão matemática ou quando terminamos uma refeição. Uma experiência singular forma "um todo e carrega em si um caráter individualizador e sua autossuficiência. Trata-se de uma experiência”.

Uma experiência não se dissipa facilmente, não evapora de maneira displicente; uma experiência é a que culmina na resolução de um problema original, formando assim um todo organizado. Embora seja desse modo, as experiências singulares não trazem nenhuma "revelação final", pois, para Dewey, não podemos contar com o apoio de uma tabela eterna de valores. Os valores a que somos conduzidos pela experiência singular são construçôes sociais contingentes, sensíveis ao contexto, às circunstâncias, à nuances da ocasião; em suma, são valores constantemente abertos à reconstrução.

É por meio dessa análise que Jim Garrison (2010, p. 25) caracteriza a reflexão como "atividade artística criativa", poiësis. O autor extrai o significado de poiësis das intervençóes de Diotima no Banquete de Platão, em que se lê: denomina-se "criação ou poesia a tudo aquilo que passa da não-existência à existência” (Platão, 1954, p. 161). Garrison (2010, p. 8-9) compreende poiesis como a arte de "chamar alguma coisa à existência”, atribuir significado a alguma coisa (ver CUNHA; PIMENTA, 2011).

O conhecimento relativo à poiessis é uma techné, palavra cujo significado é sensivelmente diferente do que se atribui ao termo theoria, vinculado à atitude de "especulação, contemplação", do qual advém o conhecimento denominado epistéme. Por envolver techné, a poiësis é um empreendimento devotado à prática, exprimindo um saber aplicável, capaz de operar transformaçóes. Poiësis, portanto, diz respeito a atribuir 
significado a alguma coisa e, com isso, transformar a própria coisa, criar novos sentidos para o mundo que nos cerca.

Para atingir essa realização, os poetas - segundo a denominação antiga - operam, antes de tudo, sobre os sentimentos das pessoas, sobre os componentes passionais da alma, não sobre ingredientes racionais, cognitivos. Sendo assim, quando Dewey afirma que a experiência nunca é “primariamente cognitiva”, ele quer dizer que a experiência é, primariamente, afetiva.

\section{CONSIDERAÇÓES FINAIS}

Seguindo as proposiçóes de Dewey, podemos dizer que existe uma conexão orgânica entre experiência e afeto. Uma experiência é algo que vivenciamos no interior de um processo reflexivo que nos mobiliza para solucionar alguma situação problemática, indeterminada, no intuito de tornála clara, definida, determinada; a solução a que chegamos, no entanto, nunca é final, definitiva. Por isso, o que confere valor a uma experiência é a sua capacidade de nos tornar mais bem equipados para experiências futuras. Para que seja assim, nenhuma verdadeira experiência acontece sem que estejamos, de fato, afetivamente envolvidos por um problema.

Essa é a proposta de Dewey para a educação: os professores deveriam propiciar aos alunos a oportunidade de ter experiências, experiências verdadeiramente significativas para eles. Para isso, os mestres deveriam operar não só no âmbito do conhecimento científico sistematizado, que é o objetivo de toda educação, mas também, e principalmente, no espaço psicológico em que se localizam os afetos daqueles a quem pretendem educar.

Mas podemos ir além. Os próprios educadores deveriam fazer de seu trabalho uma experiência, concebendo o seu ofício como um problema a ser enfrentado na prática. Sem desconsiderar as teorias, os professores deveriam fazer da vivência em sala de aula uma experiência singular. Assim, 
em vez de simples ação mecânica destinada a transmitir conhecimentos formalizados, a atuação do mestre deveria ser continuamente reinventada por meio da constante reflexáo sobre a contingência que a envolve, sobre o caráter único das situaçóes em que se desenvolve.

\section{REFERÊNCIAS}

AMARAL, Maria Nazaré C. Pacheco. Dewey: filosofia e experiência democrática. São Paulo: Perspectiva, EDUSP, 1990.

CUNHA, Marcus Vinicius. John Dewey: uma filosofia para educadores em sala de aula. Petrópolis: Vozes, 1994.

CUNHA, Marcus Vinicius; PIMENTA, Rita. Reflexão, democracia e poética em John Dewey. In: FÁVERO, Altair Alberto; TONIETO, Carina (Orgs.). Leituras sobre John Dewey e a educação. Campinas: Mercado de Letras, 2011.

DEWEY, John. Democracia e educaçâo: introdução à filosofia da educação. Tradução Godofredo Rangel e Anísio Teixeira. 3. edição. São Paulo: Nacional, 1959a.

- Reconstrução em filosofia. Tradução António Pinto de Carvalho. 2. edição. Nacional: São Paulo, 1959b.

. Experiência e educação. Tradução Anísio Teixeira. São Paulo: Nacional, 1971.

. Arte como experiência. Tradução Vera Ribeiro. São Paulo: Martins Fontes, 2010.

GARRISON, Jim. Dewey and Eros: wisdom and desire in the art of teaching. Charlotte: Information Age Publishing, 2010.

PAPPAS, Gregory Fernando. John Dewey's ethics: democracy as experience. Bloomington: Indiana University, 2008.

PLATÁO. Diálogos: Mênon, Banquete, Fedro. Tradução Jorge Paleikat. 3. edição. Rio de Janeiro: Globo, 1954.

TEIXEIRA, Anísio. A pedagogia de Dewey. In: DEWEY, John. Vida e educação. 10. edição. São Paulo: Melhoramentos, 1978.

Data de recebimento: novembro de 2013

Data de aceite: junho de 2014 
